University of Nebraska - Lincoln

DigitalCommons@University of Nebraska - Lincoln

\title{
Meso-Scale Weather and Climate Observations in Kentucky for Societal Benefit
}

\author{
Rezaul Mahmood \\ University of Nebraska - Lincoln
}

Follow this and additional works at: https://digitalcommons.unl.edu/natrespapers

Part of the Natural Resources and Conservation Commons, Natural Resources Management and Policy Commons, and the Other Environmental Sciences Commons

Mahmood, Rezaul, "Meso-Scale Weather and Climate Observations in Kentucky for Societal Benefit" (2008). Papers in Natural Resources. 1264.

https://digitalcommons.unl.edu/natrespapers/1264

This Article is brought to you for free and open access by the Natural Resources, School of at DigitalCommons@University of Nebraska - Lincoln. It has been accepted for inclusion in Papers in Natural Resources by an authorized administrator of DigitalCommons@University of Nebraska - Lincoln. 


\title{
Mesoscale Weather and Climate Observations in Kentucky for Societal Benefit
}

\author{
Rezaul Mahmood and Stuart A. Foster \\ Photographs by authors
}

\section{Introduction}

Weather and climate and their variations have played an important role in the development of human civilization. Despite groundbreaking scientific and engineering innovations during the $20^{\text {th }}$ century that create controlled environments indoors and reduce vulnerability outdoors, weather and climate significantly affect the day-to-day lives of billions of people on our planet. They impact all residents of the globe, including developed nations. It is not a coincidence that humans began observing and recording weather and climate during the very early stages of civilization. Early observations were recorded in the form of sketches and paintings, later as written descriptions, and recently as quantitative measurements using advanced instrumentation. Instruments have most commonly been used to record temperature, precipitation, air pressure, wind speed and direction, relative humidity, and solar radiation. These observations provided the foundation of our current scientific understanding of local, regional, national, and global weather and climate.

Many foundational theories of weather and climate were developed based on these data. For example, Sir George Walker wrote his key papers on the Southern Oscillation during the late 1910s. At that time, he showed that sea level pressures experienced a reversal between Darwin, Australia (low to high) and Tahiti (high to low) every five to seven years. He also found that during these pressure reversals, the Indian summer monsoon weakened and India experienced widespread severe drought and subsequent crop loss and famine. His work can be identified as one of the first modern era documentation of global-scale interactions of ocean and atmosphere. During the second half of $20^{\text {th }}$ century, climatologists found that sea surface temperature increases every three to seven years in the eastern and central Pacific Ocean, which leads to a shift in the location of convection in the Pacific and a weakening of trade winds. These changes are collectively known as El Nino. It is well known that El Nino significantly affects large-scale atmospheric circulation and seasonal weather conditions globally. Sir Walker's discoveries and subsequent findings by others have provided the basis for the current seasonal climate outlook released by the National Oceanic and Atmospheric Administration (NOAA).

Because of Sir Walker's innovations and contributions to the collection and analysis climatic data, the past century witnessed significant growth in scientific knowledge about many synoptic mesoscale ( 1 to 100 kilometers) weather and climate phenomena such as mid-latitude cyclones and urban heat islands. Other examples of inherently local or mesoscale events include severe storms that produce damaging winds, intense lightning, heavy precipitation, and sometimes hail or tornados. Even a drought episode can be fairly localized. These relatively smaller scale variations of weather and climate can pose significant challenges to emergency managers, various local government entities, weather forecasters, farmers, outdoor enthusiasts, residents of affected areas, and a variety of other stakeholders. Access to high quality real time data is essential for monitoring and accurate forecasting of these events. However, in most cases, these observations are not available in real time, and station density over regions is sparse.

Technological advances have created both the need and ability to develop dense networks of automated weather and climate observing stations, often called mesonets, which collect and disseminate data in near real time. Doppler radar sites, for example, have helped storm forecasters to provide longer lead times when issuing tornado warnings. A dense network of automated observing stations can provide critical rainfall data to aid in issuing flash flood warnings in a timelier fashion or, at the opposite extreme, monitor the severity of localized drought. Energy companies and weather-induced markets rely on locally accurate and timely air temperature data. Likewise, road surface monitoring provides information that is critical to the safety of motorists and to crews responsible for maintaining roads. These are just a few of the numerous situations involving both the public and private sectors where a mesonet (a network that provides real time mesoscale weather information) would prove valuable. Unfortunately, the current weather and climate observation network maintained by NOAA does not satisfy many of these requirements.

The mission and purpose statement for Western Kentucky University (WKU) speaks to the University's responsibility to support economic development, quality of life, and enhanced education within the state and well beyond. Recognizing these unmet needs for weather and climate monitoring, the Kentucky Climate Center (KCC), housed in the Department of Geography and Geology, undertook an initiative in 2006 to develop the Kentucky Mesonet. This network will consist of nearly 100 stations located across the state of Kentucky. Each station will collect and disseminate data at near real time for precipitation, temperature, relative humidity, wind speed and direction, solar radiation, and leaf wetness. Except for rain gauges, instruments will be mounted on a 10-meter tower. Most of the stations will also collect soil moisture and soil temperature data at five different depths of up to one meter below the surface. The 
network will initially collect data every five minutes and transmit it at least every fifteen minutes. Here, we present further background and rationale for developing this network and its potential benefits.

\section{Background}

The Federal government has taken the lead in observing and archiving weather and climate records for the United States. As early as 1818, the United States army recognized the need to collect weather observations in order to develop an understanding of climate. The Cooperative Weather Observer Network (popularly known as the COOP), operated by the National Weather Service (NWS), dates to the 1890s and represents the backbone of the country's weather and climate observing activities. COOP observers are volunteers who receive training from NOAA on how to observe, record, and communicate measurements. These observers most commonly interact with their local NWS forecast offices and the National Climatic Data Center (NCDC). The latter is the national repository of recorded weather and climate data.

COOP observers primarily record daily maximum and minimum temperatures and daily total precipitation. Historically, these observations are submitted on paper forms at the end of each month, undergo baseline quality checks to assess the accuracy of the data, and become available as part of the official climate record some four months later. In many cases, observations are also reported to local NWS offices on a daily basis, and more frequently in the case of significant precipitation events. Overall, however, much value is lost because the data are not readily available immediately to a broad array of stakeholders.

Through the years, as population has become more mobile and more urbanized, it has become increasingly difficult to find reliable, long-term cooperative observers willing to volunteer. In addition, limited funding has made it difficult to maintain the quality of the COOP network. Site by site evaluation of the network reveals a number of high quality stations with dedicated weather observers. Nevertheless, the COOP network suffers from a number of shortcomings, including problems with sites that have poor instrument exposures and instruments that are not well calibrated or are broken. In many cases, poor historical metadata and undocumented observing practices at individual sites make it difficult to assess the quality of observations.

During on-site visits, we have found temperature sensors located over a driveway and grilling stove, next to an asphalt parking lot, and next to brick buildings. These temperature sensors would surely record inaccurate temperature observations. In another case, we also found a temperature sensor that was located at the bottom of a narrow valley of a creek where cold air can drain, and this site reported the record low temperature for Kentucky. COOP observers frequently prefer to locate the instruments close to their home for convenience of data collection, and this has become increasingly likely since the installation of sensors that use cables connected to an indoor readout device. In yet another case, we found a precipitation gauge located under a canopy. This COOP station observed the longest period of "no precipitation" in Kentucky and was entered into the official climate record for Kentucky.

Station moves, absence of documentation of these relocations, and poor metadata are among other problems that have plagued this network. Some stations have been moved several times during the period of record. As a result, station exposure has changed abruptly. This has been reflected in historical measurements that show sudden changes in the records. In many cases, significant changes in land use and land cover have been recorded in the general area. Due to the absence of necessary records and station metadata, it has become difficult to trace the impacts of these changes on historical climate records.

To overcome some of these problems, the NWS established the Automated Surface Observing System (ASOS) and

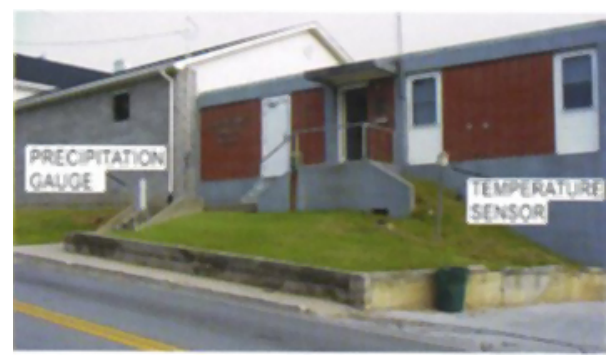

Precipitation and temperature measuring instruments located in front of a building on sloping surface and close to an asphalt-covered road. This site is owned by NOAA and located in Greensburg, Kentucky. It is clear that the exposure of instruments is undesirable. This type of exposure to various structures results in severely biased measurements. began deploying it in the 1990s. With advancements in technology, instruments can be installed in the field which collect atmospheric data, store data in a data logger, and are able to communicate measurements through an appropriate communication system. In most cases, these stations are located in airports, and station density is very low. For example, there are only nine ASOS stations currently located in Kentucky.

In addition to these weather and climate observing networks, Kentucky and other states usually have networks with a limited number of stations maintained by various state level agencies, such as departments of transportation. Typically, these stations measure only a limited number of atmospheric parameters and data are not easily available to the public. In most cases, these data do not go through quality checks and are not archived. Thus, they are of little use in weather and climate research and for long-term societal decision-making and planning. Moreover, these observation networks use many different types of instruments that are often not well maintained. As a result, bias associated with a particular measurement cannot be traced back. Hence, while these networks meet some operational needs, they are of very limited value for research and long-term tracking of climate variability and change.

\section{Kentucky Mesonet}

The KCC, a member of the National Climate Services Partnership, is developing the Kentucky Mesonet to collect and make available quality, high-value weather and climate data for the Commonwealth of Kentucky. As already stated, this network will collect and provide near real-time meteorological and hydrological data as an aid to forecasters, decision makers, researchers, and other users. And it will help to establish a detailed record of Kentucky's dynamic weather environments for future generations. Mesonet data will be broadly available and will contribute a wide range of benefits for the people of Kentucky. In addition, the data will also be made available to others nationally and globally.

Kentucky is not the first state to recognize the need for a mesonet. The Oklahoma Mesonet is an excellent example that has gained national and international prominence through its service to a broad array of users (Shafer et al., 2000). A somewhat similar network, operated 
through the High Plains Regional Climate Center (hprccl.unl.edu), provides significant support for the agricultural community in crop management, drought monitoring, and weather and climate monitoring. The success of these networks provided the impetus for the development of the COOP Modernization project of NOAA and the development of a 'National Mesonet' (NERON Project). However, due to funding priorities, the latter project is currently limited to parts of the Northeastern US

These activities and their proven utility gave us the encouragement to pursue development of the Kentucky Mesonet. For operational purposes, the Kentucky Mesonet has adopted the model of the Oklahoma Mesonet and our instrumentation package is based largely on the NERON and Climate Reference Network (CRN). The collection of research quality data is necessary to realize the full potential of the Kentucky Mesonet. While this requires investment in and configuration of quality instruments that are compatible with the standards of Federal networks, it also requires identification and documentation of quality observing sites. Hence, a key step in building the Kentucky Mesonet is to ensure selection of sites that provide desirable exposure of instruments. We use the site selection criteria recommended by the World Meteorological Organization (WMO).

The $\mathrm{KCC}$ is currently working in collaboration with Kentucky's Area Development Districts (ADDs) and NWS representatives to identify potential sites. We expect to survey two to three candidate sites for each final selection; hence, a total of about 200 to 300 site surveys will be required for a network of 100 stations. Kentucky's 15 ADDs serve as a link between federal/state government agencies and local governments. Thus, they provide an opportunity to engage local officials and stakeholders in the site identification process. By building partnerships, we can tap local knowledge and expertise to help in identifying quality long-term sites that may offer opportunities to serve other local needs. The Kentucky Climate Center has developed an informational packet tailored to each ADD to help educate local officials concerning the stringent site requirements for stations in the Kentucky Mesonet.

At the end of the survey in a given region, a regional site selection team (headed by representatives of the Kentucky Climate Center and NWS) combines information from site survey ratings with input from relevant stakeholders to make final decisions on the sites for mesonet stations. Subsequently, we initiate contact with the landowner of each selected site to confirm permission for installing a station. Upon agreement of such action, a legal document is signed by both parties for access and maintenance of the station. About 50 sites have been surveyed during the preparation of this paper. Site preparation has been completed for the installation of three stations and one test station is currently fully operational on the test site.

The site selection process is being aided by the use of geographic information system (GIS) tools built upon a base map that includes high resolution digital elevation models and digital orthophotographs available through the Kentucky Division of Geographic Information. The $\mathrm{KCC}$ has extensive experience in developing GIS-based metadata (known as the GeoProfile) for NWS COOP stations (Mahmood et al., 2006). This method is currently in use for site selection and building station metadata.

A critical component of site selection is availability of continuous communication with Mesonet stations from a home location at Western Kentucky University. Recall that this network will transmit data every

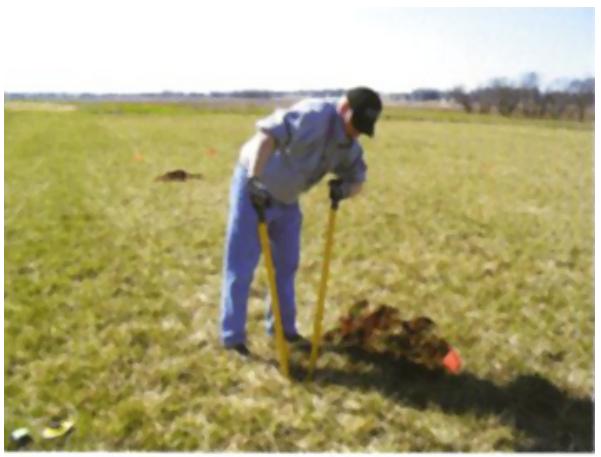

A Kentucky Mesonet technician begins preparation of the ground for the installation of the instrumentation tower.

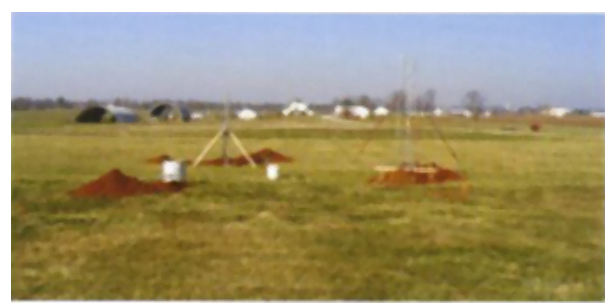

The installation of the instrumentation tower, solar panels, and weighing bucket rain gauge is completed. Solar panels help provide power to the station for the operation of instruments. fifteen minutes to secure computers at WKU for dissemination to the public and a variety of stakeholders, including the National Weather Service and emergency managers. Consequently, a reliable communication connection is essential. For this purpose, after months of investigation and research, it was decided that digital cellular connections should be used to communicate data. The cellular connections also provide an opportunity to use two-way communication. If the Mesonet administrators decide to make any changes in, for example, data collection procedures, it can be done through the system using one keystroke rather than traveling to 100 sites.

To ensure research quality data, detailed and strict quality assurance and quality control $(\mathrm{QA} / \mathrm{QC})$ procedures are being implemented. These procedures will be executed near real-time as data arrives. Questionable data will be flagged and further assessment will be conducted to identify cause(s) of the bias, and measures will be taken to eliminate additional bias in the future. Obviously, the network is using its own personnel to install and maintain instruments. However, to further ensure the quality of data, the network is also developing its own capability to test and calibrate instruments. Again, to avoid existing problems with other weather and climate observing networks, each single piece of equipment will be tracked through its lifetime within the network. This will help build strong metadata and help track and reduce potential bias in the data. Technicians and graduate student assistants will make multiple site visits to each station on an annual basis. During these visits, they will cut vegetation, check instruments, swap instruments (if necessary), complete field calibration (if necessary), take pictures of the site, and provide detailed metadata documentation.

\section{Societal Benefits}

The availability of research quality data with high spatial and temporal resolution will provide an unprecedented opportunity to conduct basic and applied research in weather and climate science. In the context of recent climate change issues, the data collected will be valuable in the future to investigate various unresolved issues of atmospheric science. Obviously, Mesonet data will be used to monitor various weather and climate related hazards. The NWS forecast offices of Kentucky will be using mesonet data, and 


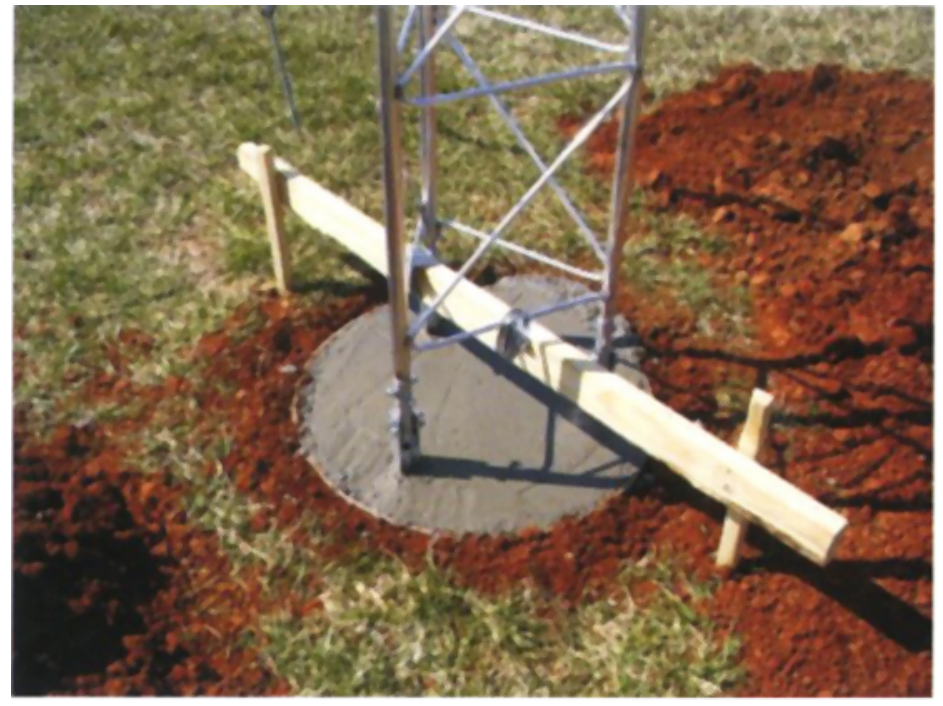

The base of the instrumentation tower.

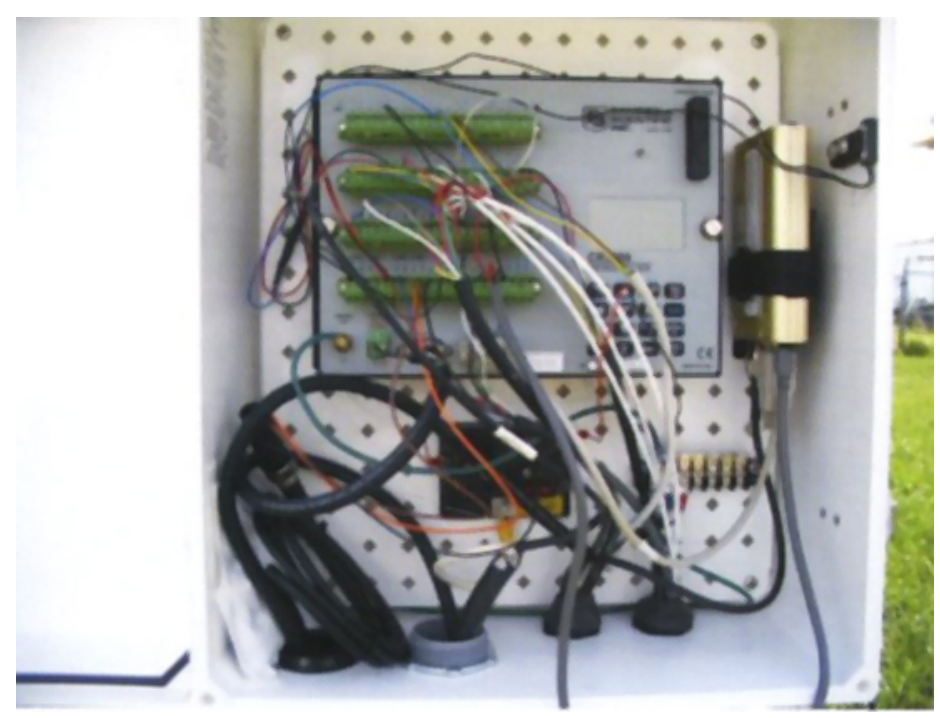

Data logger and communication equipment within the enclosure.

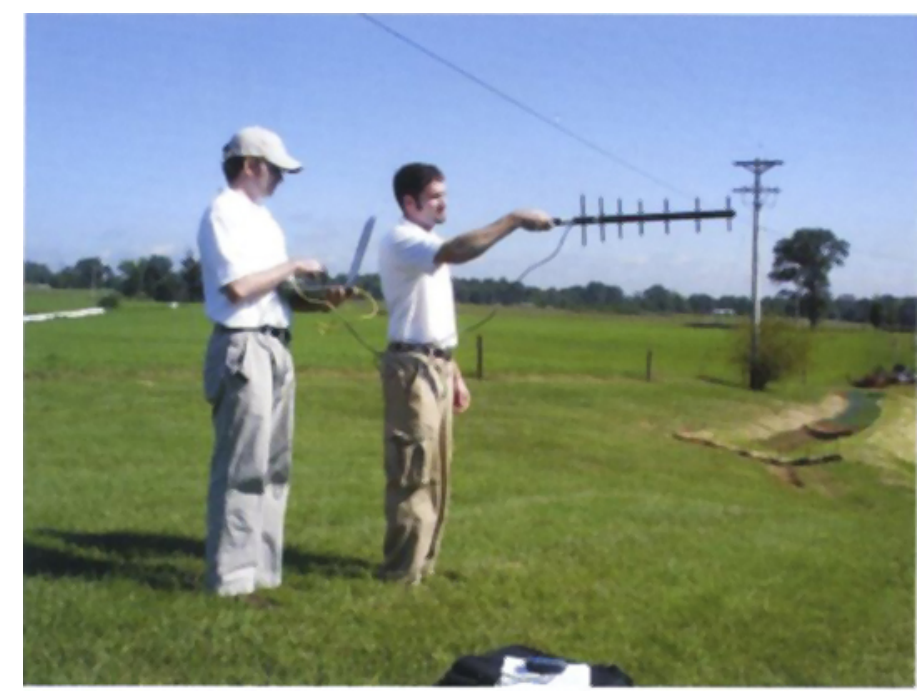

Graduate students conducting site surveys.

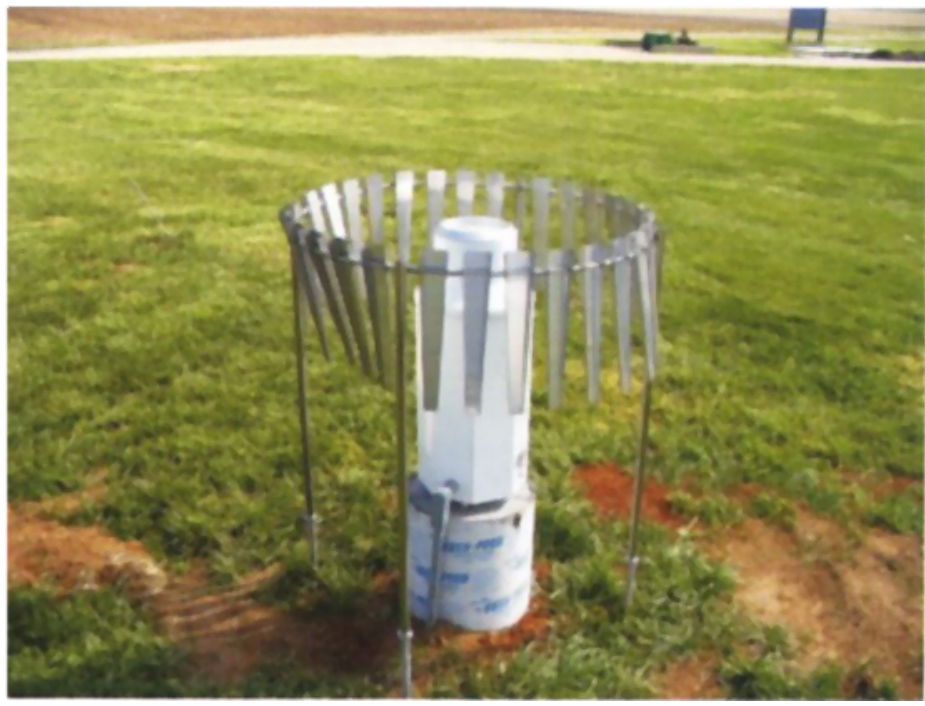

Weighing bucket rain gauge with alter shield.

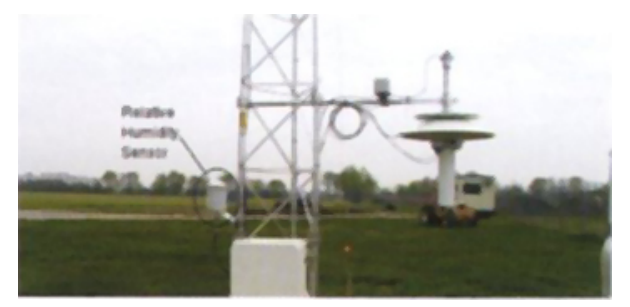

Relative humidity measuring sensor.

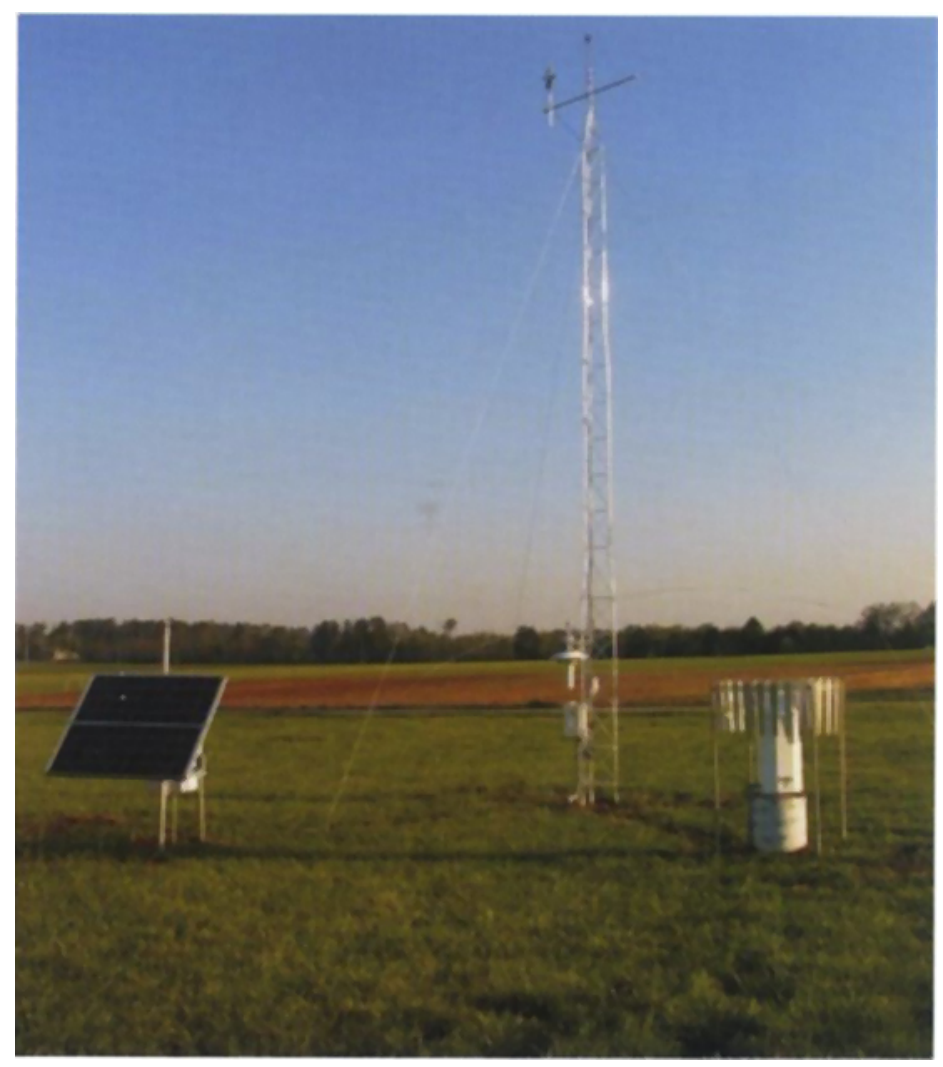

Completed Mesonet test station showing the tower with instruments, weighing bucket rain gauge with single alter wind shields, and solar panels. Wind shields allow for the reduction of winds on rainfall measurement known as undercatch. Typically, wind causes lower rainfall measurements. 


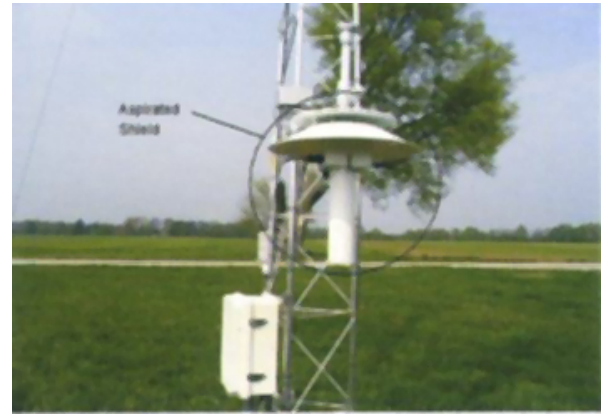

Aspired shield for temperature sensor. The white box contains data logger and communication instruments. Data logger stores the data measured by the instruments.

we expect that high resolution near realtime data will help improve the accuracy of forecasts and warnings.

The data will be available to K-16 students in near real-time through the World Wide Web and can be used in the classroom to teach science. Note, WKU is launching a new Bachelor of Science degree in meteorology, partly based on the promise of Mesonet. In addition, the Mesonet is already working in collaboration with the Kentucky Geographic Alliance (KGA) to train $\mathrm{K}-12$ teachers. It is also planning to provide lesson plans and other curricular support for K-12 teachers through a variety of activities, including workshops. In the future, many supporting materials will be delivered through the Web. Graduate and undergraduate students from WKU are currently participating in these activities, with graduate students taking the lead in site surveys and in the process learning issues related to data quality and their implications in research. The approach of the Kentucky Mesonet is such that graduate and undergraduate students are and will be actively participating in every segment of the project.

Various web-based products will be developed for emergency managers so that they can effectively use weather information to save lives and properties. They will attend workshops and refresher courses to learn and stay up-to-date on new materials. With the expected expansion of Mesonet activities, products will be developed for the general population, farmers, agricultural extension personnel, water resources managers (drought, flood, water quality, and water pollution), health care professionals (heat stress, air pollution, and insect- and water-borne disease outbreaks) and a variety of other local and state-level entities. Many of these products can be accessed using near real-time weather data and will be interactive. GIS will play a significant role in data mining, product development, and data visualization. Moreover, it is an example of local efforts that are inherently designed to produce a global impact. In summary, the Kentucky Mesonet is providing a unique opportunity, where teaching, research, and outreach activities are intricately interwined for broader societal benefit.

\section{Acknowledgement}

The authors would like to thank Megan Ferris for technical assistance. This work benefitted from the NOAA grant\# NA06NWS4670010.

\section{References}

Mahmood, R., Foster, S.A., Logan, D. 2006 The GeoProfile Metadata, Exposure of Instruments, and Measurement Bias in Climatic Record Revisited. International Journal of Climatology. 26: 1094-1124.

Shafer, M.A., Fiebrich, C.A., Arndt, D.S. Fredrickson, S.E., and Hughes, T.W. 2000. Quality Assurance Procedures in the Oklahoma Mesonetwork. Journal of Atmospheric and Oceanic Technology, 17:474-494.

\title{
McColl FAMILY FELLOWSHIP
}

\author{
Tenth Annual Competition
}

The McColl Family Fellowship, given by Dr. and Mrs. Robert W. McColl, consists of round trip air fare to any place in the world of the candidate's choosing. The candidate must secure funding for other expenses from other sources. The only obligation of the Fellow is to write an article based on the visit abroad that is suitable for publication in FOCUS on Geography magazine and that is submitted to the editor within six months upon return from the trip.

As is true of all FOCUS on Geography authors, candidates must be geographers or others "who think like geographers and write like journalists." Selection is by a committee chosen by the AGS Council. Fellowships for this year were won by Russell Fielding, a doctoral student at Louisiana State University, for research on whaling communities in Newfoundland, and Joel Harter, an assistant professor at the University of New Hampshire, for work on communities surrounding Kibala National Park in Uganda.

Applications for the McColl Family Fellowship for the year 2009 must be received in the AGS offices by October 15, 2008. They are to consist of the candidate's curriculum vitae; a covering letter of no more than three pages that describes a) the proposed trip, b) the reasons for selecting that itinerary, and c) the candidate's particular competence for doing fieldwork there; and a statement of the sum requested. Samples of writing similar to the style of FOCUS on Geography may be included.

Applications should be sent to: McColl Family Fellowship Committee

The American Geographical Society

120 Wall Street, Suite 100

New York, New York 10005-3904

For further information contact Mary Lynne Bird at (212)422-5456 voice, (212)422-5480 fax, MLBird@amergeog.org or see the AGS website at http://www.amergeog.org 